\title{
PHYTOCHEMICAL RESEARCH OF FILIPENDULA ULMARIA AND FILIPENDULA HEXAPETALA
}

\author{
(c) Kruglova M.J, Kruglov D. S., Fursa N.S.
}

${ }^{1}$ Novosibirsk State Medical University, Russia

${ }^{2}$ Yaroslavl State Medical Academy, Russia

The herbal medicines made from Filipendula ulmaria Maxim. are used in folk and applied medicine. They have anti-inflammatory and astringent activity. Along with this plant, $F$. hexapetala Gilib. is also a wide-spread plant of the genus Filipendula. The aim of work is the comparative phytochemical research of above-ground part of these plants. The above-ground parts of investigated plants were collected in Novosibirsk region in flowering stage. The collected raw materials were dried before the measuring. The amount of polysaccharides, amino acids and phenol compounds were measured by means of HPLC. Identification of components was done by the way of comparison with the standard substances. As a result it was established that both species have similar monosaccharide and amino acid structures (The amount of polysaccharides and amino acids was calculated for the absolutely dry raw material and equaled $7,0-8,5 \%$ and $8,3-10,3 \%)$.

For the first time methylcoumarin was discovered in the investigated plants. Also it was established that qualitatively the primary and secondary metabolites of two species of Filipendula are alike, which is in agreement with
Table. The content of phenol compounds F. ulmaria and F.hexapetala

\begin{tabular}{|l|c|c|}
\hline \multirow{2}{*}{ Compound } & \multicolumn{2}{|c|}{ Relative amount, \% } \\
\cline { 2 - 3 } & F. ulmaria & F. hexapetala \\
\hline Gallic acid & 18,06 & 22,23 \\
\hline Catechine & 3,50 & 2,66 \\
\hline Chlorogenic acid & 9,57 & 3,77 \\
\hline Neochlorogenic acid & $-* 1$ & 3,93 \\
\hline Cichoric acid & 4,25 & 4,04 \\
\hline Ferulic acid & 1,26 & - \\
\hline Hyperoside & 0,90 & 3,42 \\
\hline Isorhamnetin & - & 0,31 \\
\hline Apigenin & 0,47 & - \\
\hline Methylcoumarin & 4,53 & 4,82 \\
\hline * 1 - it is not revealed & & \\
\hline
\end{tabular}

known data. There are only insignificant differences in the quantitative amount of components and this fact allows to assume a similar pharmacological activity of phytomedicines which can be made from both species studied.

\section{MODERN REQUIREMENTS TO VOLUME OF PRECLINICAL PILOT STUDIES OF PHYTOPREPARATIONS}

\section{(C) Krutikova N.M, Verstakova O. L., Turyanskaya A. Y., Olenina N. G., Miheeva N. S.}

FGBU Scientific Center on Expertise of Medical Application Products of the Ministry of Health and Social Development of the Russian Federation, Moscow, Russia

The legal basis for State Registration (SR) of phytopreparations (FP) in Russia are the Federal law "On the circulations of medicines" of April 12, 2010 No. 61-FZ, departmental orders, instructions and other regulations of Ministry of Health and Social Development (MHSD). Original FP (OFP), generic FP (GFP), innovative combinations of registered FP, registered FP in new pharmaceutical forms $(\mathrm{PhF})$, new dosage and new administration way are subject to SR in Russia. Generally FP contain a complex of biologically active substances determining the main pharmacological action (PhA) of FP; possess a broad spectrum of PhA; quality, efficiency and safety of FP depend to manufactiring technology. Preclinical pilot studies (PPS) of pharmacological activity and safety of new FP should start after the development on standardization of starting materials, substance and finished product. The plan of necessary PPS is defined by origin of PhF, chemical composition, data on efficiency and safety of starting materials, a type of declared specific activity, etc. In general PPS includes study of specific PhA, overall pharmacological activity (effects on the main organs and systems), systemic toxic properties (acute and chronic toxicity) and specific types of toxicity (allergenic and local irritative effect, reproductive toxicity, mutagenicity, carcinogenicity, immunotoxicity; studying of toxic properties on immature animals for FP used in pediatrics). For FP made of medicinal plant raw materials in a PhF of powder packed in filter-packages (Fpac) carrying out comparative PPS of equivalence of the content of active substances in infusions or decoctions made of a powder and registered $\mathrm{PhF}$ is necessary. For GFP (more than 20 years in the pharmaceutical market Russia) the simplified scheme of PPS confirming its pharmaceutical and biological equivalence with OFP, including studying of comparative chronic toxicity of finished $\mathrm{PhF}$ on condition of availability of data on efficiency and safety of application is allowed. 